\title{
Public Procurement
}

\section{Establishing Procurement Review Bodies}

\section{CONTENTS}

- Importance of the review and remedies system

- Main institutional models

- Key requirements of a specialised review body

- $\quad$ Administrative complaints to the contracting authority/entity

- $\quad$ Status and independence of the specialised review body

- $\quad$ Other important practical issues

- $\quad$ Further reading 


\section{Importance of the review and remedies system}

The main objective of a public procurement complaints review and remedies system is to enforce the practical application of public procurement legislation by ensuring that violations of this legislation and intentional or unintentional mistakes of contracting authorities/entities can be corrected. A well-functioning procurement review and remedies system is in the interest of all stakeholders - economic operators, contracting authorities/entities as well as the general public.

The public procurement review and remedies systems of EU Member States have to be established and developed on the basis of the specific requirements of the EU Public Procurement Remedies Directives 89/665/EEC and 92/13/EEC, amended among others - by Directive 2007/66/EC, the Treaty on the functioning of the European Union and the case law of the Court of Justice of the European Union (CJEU).

According to the aforesaid and to other international standards as well, such a system has to provide aggrieved tenderers and candidates with remedies, which must be:

- Rapid;

- Effective;

- Transparent;

- Non-discriminatory.

Although the EU Directives are addressed to EU Member States, candidate countries and some EU partner countries are developing new (sound and efficient) remedies systems that are based on the general principles promoted by the EU Directives. This Brief aims to give general guidance - in particular to policy-makers in those countries on one of the most important elements to be taken into consideration during the development and implementation of a remedies system: the establishment of the review body (or bodies).

This Brief first provides a description of the main institutional models in the EU, without attempting to evaluate their respective advantages/disadvantages or to recommend any particular institutional arrangements. It then highlights the key requirements provided in the EU Directives and the CJEU case law for "specialised" review bodies. The last sections of the Brief mainly address aspects of good practice, such as the ways of ensuring the independence of review bodies and the ways of dealing with other important issues involved in the establishment of a review body.

\section{Main institutional models}

There are a number of different models for the establishment of a remedies institutional framework and different approaches for enforcement in EU Member States, due to the diversity of national legal traditions; it is thus difficult to affirm that one model is better than another. Since all Member States enjoy institutional autonomy, each one is free to choose the most suitable option for ensuring the effective review of public procurement contracts. Member States are not required to change their institutional structure in order to implement, apply and enforce EU law, but they may use the national channels and mechanisms that are already in place, provided that they comply with EU law. At the same time, nothing impedes a Member State from setting up new, specialised administrative bodies with the authority to provide remedies

Provided that Member States ensure the effective review of public procurement contracts, they are free to confer remedies functions to any of the following bodies: 


\section{- Regular courts;}

\section{- Specialised administrative bodies;}

\section{- A combination of the two.}

The Remedies Directives provide that complaints may be brought before "separate bodies responsible for different aspects of the procedure". Indeed, in the majority of Member States, the model chosen is a combination of various review bodies that are responsible for different aspects of review. For instance, certain complaints - in particular those involving damages - can only be reviewed in the regular courts, while in certain jurisdictions, the specialised procurement review body may review complaints without deciding on damages, if damages are concerned. Frequently, the conclusion of the contract is the point at which the two paths in such a system separate ${ }^{1}$.

With regard to the regular courts, the Remedies Directives do not require the review to be conducted in civil or administrative courts. According to the procedural rules in each country, either option or both of them may be envisaged.

In Belgium, France, Ireland, Lithuania, the Netherlands, Portugal, Sweden and the United Kingdom, the review of public procurement decisions is the task of regular courts exclusively.

Moreover, one Member State at least makes a clear distinction between contracts covered by Directive 2004/18/EC and contracts covered by Directive 2004/17/EC. As a result of such a distinction, in Belgium administrative courts deal with public procurement disputes concerning the first category of contracts, and civil courts deal with disputes involving second-category contracts.

In other Member States, the jurisdiction depends on the (private or administrative) nature of the relevant contract. France is an example where both the civil and administrative courts are involved in the review process, but the distinction was made in a different manner than it was in Belgium, as the civil courts only review the procurement decisions of privately owned utilities.

A substantial difference between the various models concerns the level of the firstinstance review body. The first instance refers in some cases to the lowest-instance administrative courts and in other cases to a higher degree of jurisdiction. The level of the first instance may have implications on cost, speed and proximity to the parties. Proceedings in a high-level court may be costly, time-consuming and far from the region in which the procurement contract was carried out. These factors may deter tenderers from filing complaints. In contrast, proceedings in a low-level court may be cheaper, quicker, and closer to the region of the procurement contract implementation; on the other hand, these bodies may lack experience and expertise.

Specialised public procurement review body do exist in approximately half of Member States. These bodies are usually of a non-judicial or quasi-judicial nature (namely similar to courts in the meaning of TFEU art. 267) and have the function of a first-instance review body. With some exceptions, the decisions of the specialised 
review body are binding, subject to appeal in civil or administrative courts that may annul or change the decision in the second instance.

In many Member States the second instance is the last instance, but a group of Member States have third instances of judicial review, e.g. Estonia, Latvia, Lithuania, Netherlands, Slovakia, Sweden and the United Kingdom.

Several important advantages recommend the establishment of specialised procurement review bodies, particularly in candidate and potential candidate countries, as well as in any other country interested in implementing an efficient review system:

- The procedure is usually simpler and quicker than is the case in regular courts. These characteristics ensure the conditions for better fulfilment of the "rapidity" criteria, which must be a specific feature of the remedy system.

- The members of the specialised review body deal exclusively with procurement cases. As a result, they have the opportunity to very quickly gain specialised expertise and to become familiar with contract award procedures and other related issues.

- The cost involved when regular courts review complaints may be much higher than it would be in specialised review bodies, due to the length of the procedure and the need for legal representation.

\section{Key requirements of a specialised review body}

Though usually non-judicial, a specialised public procurement review body may also be of a judicial character.

Judicial character: The case law of the Court of Justice of the European Union $(\mathrm{CJEU})^{2}$ has established the main requirements on the basis of which a body responsible for providing remedies should be considered as having a judicial (or quasijudicial) character. The Court took account of a number of factors, such as whether the body is established by law, whether it is permanent, whether its jurisdiction is compulsory, whether its procedure is inter partes, whether it applies rules of law and whether it is independent.

- The body is established by law. In many EU Member States, the establishment of the review body is provided for in a dedicated chapter of the public procurement law (PPL). That provision does not mean that the solution to adopt a special law - covering only the institutional aspect - is not a good solution as well. The legal provisions should regulate various aspects ensuring the functionality of the body, including for example provisions concerning the review body's competences, the appointment and dismissal of its members, the qualifications required of the review body's members, conflict-of-interest provisions, a predetermined system for the distribution of cases, and procedural requirements.

Austria is a particular case. Under the federal system set forth in the Austrian Federal Constitution, ten different review bodies deal with appeals against 
contracting authorities/ entities. Hence the procedures to be followed are laid down, on the one hand, in nine different federal state (Länder) laws on procurement review at regional or municipal level and, on the other hand, in the federal PPL.

- The body is permanent. The body is not established on an ad hoc basis. Its members remain in their position for a determined number of years. This requirement does not exclude the possibility of having several panels within the review body dealing with cases according to a predetermined distribution system.

- The body's jurisdiction is compulsory. Any decision/determination made by the review body has to be enforceable. In particular, the body is conferred with powers to:

- Impose interim measures, with the aim of correcting the infringement or preventing further damage, including measures to suspend or ensure the suspension of the tender procedure or the implementation of any decision taken by the contracting authority/entity;

- Set aside or ensure the setting aside of any decision taken unlawfully, including the removal of discriminatory technical, economic or financial specifications in the tender notice or in tender documentation.

The authority to award damages is not a mandatory condition, and it is recommended to grant this authority to higher courts.

An exception can be noted in Denmark, where the Complaints Board is empowered to award damages. However, it is worth mentioning that the number of complaints in Denmark is very low, and the workload does not affect the requirement to ensure the rapidity of remedies. The award of damages is subject to a prior decision on the substance of the case, e.g. a decision upholding the complaint against an infringement of the applicable public procurement rules. Claims for damages are decided in accordance with the general principles of Danish law. Depending on the circumstances of the case, damages may amount to the tendering costs or to lost profits.

- The procedure before the review body is between the parties (inter partes). The general adversarial rules must be observed in all cases. All interested parties are given an adequate opportunity to present the facts and evidence, and each party should have the right to respond or to challenge all evidence and arguments presented by the other party. Oral hearings provide a better opportunity for both parties to address the other party's position, but an acceptable alternative is to allow the parties to submit written statements during the review procedure. Both parties must have access to the review proceedings file, with the exception of confidential information.

As a matter of principle, hearings of the Hungarian Public Procurement Arbitration Board are held in an open session, but the Council may decide to conduct in camera proceedings when this privacy would be necessary for reasons of state or professional or business secrecy. Subject to a few exceptions, which are usually due to business secrets, access to the procurement file is fully guaranteed to all parties involved. 
- The body applies the rules of law. When it takes decisions, the body is required to apply the provisions governing the award of public contracts, which are laid down in the EU Directives and in the national legislation adopted to transpose them. This requirement is closely related to the first requirement (the body is established by law) because a strong argument for demonstrating that the body fulfils this requirement could be the fact that the general procedural rules ensuring the functionality of the body are themselves provided in the law.

- The body is independent. This requirement covers many aspects institutional, financial - but the main principle is that the review body carries out its task independently and under its own responsibility, and that its members are subject only to observance of the law (more details are presented in the next section of this Brief).

Non-judicial character: In the case where bodies responsible for review procedures are not judicial in character the award of public contracts may be reviewed in the first instance by such bodies, but the EU Remedies Directives provide for some safeguards.

First of all, where bodies responsible for review procedures are not judicial in character, written reasons for their decisions must always be given.

Furthermore, in such cases, the decisions made by bodies not having a judicial character must be subject to judicial review or review by another body, which is a court or tribunal within the meaning of Article 177 of the EEC Treaty and independent of both the contracting authority and the review body. Such an independent body must satisfy the particular requirements of the second subparagraph of Article 2(8) of Directive $89 / 665 /$ EEC. $^{3}$ (Basically, it must fulfil all of the six requirements presented above).

The public procurement review and remedies system in Cyprus can be subdivided into three elements: a complaint to the contracting authority, non-judicial review through the Tenders Review Authority (TRA) and judicial review through the Supreme Court of Cyprus. The TRA was set up with the power to review any decisions taken by contracting authorities prior to the conclusion of any public contract for an alleged infringement of the law. Hence it is a specific public procurement review body independent from the government. However, the members of this body do not have a status that is comparable to that of judges. The TRA has five members, including the chairperson. Any person aggrieved by a decision of the TRA or by any decision taken by a contracting authority before or after the conclusion of the contract can challenge such a decision before the Supreme Court of Cyprus. The members of the Supreme Court and its chairperson are judges, and their status is governed by the Constitution. The Court fulfils the requirement for a court of law set forth in Article 177 of the EEC Treaty.

Rules under the Government Procurement Agreement (GPA). Fundamental requirements for public procurement review and remedies procedures were established 
by the 1994 World Trade Organization (WTO) Agreement on Government Procurement (and also by the UN Commission on International Trade Law - UNCITRAL - Model Law, updated in 2011). These basic function indicators set a foundation on which governments can build remedies institutions and review procedures to accommodate public interest in the efficient use of public expenditure at the same time as the interests of the private stakeholder participating in the award procedures.

It is useful to highlight that the WTO Agreement for Public Procurement contains similar principles regarding review bodies as those provided by the EU legislation. It is true that the case law of the Court of Justice of the European Union (CJEU) offers many more details on the interpretation of the general principles, applicable in specific circumstances, but the similarities between the EU and the WTO on how to address the issue of review bodies are worth emphasising as an example of good practice, recognised as such at the international level.

According to the WTO Agreement: "Challenges shall be heard by a court or by an impartial and independent review body with no interest in the outcome of the procurement and the members of which are secure from external influence during the term of appointment. A review body which is not a court shall either be subject to judicial review or shall have procedures which provide that:

(a) Participants can be heard before an opinion is given or a decision is reached;

(b) Participants can be represented and accompanied;

(c) Participants shall have access to all proceedings;

(d) Proceedings can take place in public;

(e) Opinions or decisions are given in writing with a statement describing the basis for the opinions or decisions;

(f) Witnesses can be presented;

(g) Documents are disclosed to the review body".

\section{Administrative complaints to the contracting authority/entity}

The legislation in some EU Member States provides for the obligation (or only the possibility) to:

- Lodge a prior administrative complaint to the contracting authority/entity that committed the alleged breach of public procurement law; or

- Notify the contracting authority/entity of the intention to seek review.

Both of the above-mentioned obligations/possibilities are optional according to the EU Remedies Directives.

An option to file a complaint directly to the contracting authority may offer certain advantages, especially in cases where a genuine and obvious mistake rather than a deliberate breach of public procurement law is the reason for the dispute. The tenderer can avoid confrontation with the contracting authority because the latter would have the chance to correct the mistake. This solution might be the quickest way of correcting the violation and makes it possible to avoid the costs involved in review proceedings. 
Although this kind of rule could be useful in practice, the prior complaint to the contracting authority/entity is nevertheless not regarded as a first stage of the review process, according to the Remedies Directives.

A disadvantage is that waiting for a contracting authority/entity to decide on a complaint is time-consuming and can prolong the overall review procedure. However, in the event that a prior notification has been sent to the contracting authority/entity, in parallel with the submission of a complaint to the review body, there is no obligation to wait for the decision of the contracting authority/entity. This is one reason why some Member States require economic operators that are seeking quasi-judicial or judicial review to send a copy of their complaint or lawsuit only to the contracting authority/entity in question, the latter keeping the opportunity to correct the violation themselves before entering into review proceedings. (For more details, see Public Procurement Review and Remedies Systems in the European Union (SIGMA Paper No. 41, 2007).

\section{Status and independence of a specialised review body}

As a requirement of the Remedies Directives as well as a matter of international best practice, the independence of the review body can be considered as a cornerstone for ensuring credible results of the remedy procedures against public procurement decisions.

The issues related to independence should be addressed on two levels:

- Independence of the review body as an institution;

- Independence of the members of the review body.

With regard to the institution, whether the specialised review body has or not an independent legal status, it has to be (i) independent from the parties of procurement procedures - contracting authorities/entities and economic operators; and (ii) functionally independent of the government.

Even if the review body is technically independent of contracting authorities/entities, it still forms part of the state apparatus, so there will always be a residual concern that it is not fully independent from the government. The failure to guarantee such independence of action would lead to a lack of credibility, which would have serious implications for the procurement system as a whole and for the tangible benefits that a well-functioning system was designed to offer. If the review body was unable to enforce procurement regulations against defaulters, or even if it was perceived to not be able to do so, aggrieved tenderers would see no benefit in filing complaints, and breaches of the regulations would go uncorrected.

For those reasons, the status of the review body is also linked to its location within the governmental hierarchy. As long as the review body is under the supervision of a minister, it would be difficult to demonstrate the real independence of this institution and of its staff, who must be protected from undue political interference. Even if the connections with a ministry are limited to administrative issues only, an unavoidable consequence of this link is the fact that the perception of tenderers might be that the review body is still part of the hierarchy and that its independence and neutrality could be affected at any time. The review function presupposes the power of the institution to make quasi-judicial decisions (including the award of compensation) against the government. It is open to question whether a ministry would have the power and/or credibility to make such decisions.

Consequently, it appears that the best solution is to place the review body outside a ministry, preferably as a separate institution, and in any event - even if it is not possible 
to ensure "absolute" independence - without any hierarchical positioning within the governmental apparatus and mainly as a means of preserving its independence and neutrality ${ }^{4}$.

In general, modern state administrative systems require a separation of powers within the administration in order to guarantee accountability, due process and probity. Those responsible for policy making, interpretation, implementation and advice are thus not the same as those responsible for enforcement (including the review and remedies function). With very few exceptions, in all of the EU Member States where specialised review bodies have been established, those institutions have a clear and exclusive responsibility to provide remedies. It is very important to ensure the separation of powers and competences within the public procurement system in order to avoid any conflict of interest and to generate trust in the system.

In many countries that have started to build new public procurement systems, in the first stage the regulatory body (Public Procurement Office/Agency/Authority PPO/PPA) has also been granted the powers of a review body for public procurement decisions.

If the regulatory body is tasked, according to the law, to counsel contracting authorities/entities, it might sometimes be faced with its own advice. This situation would be even more complicated if that body were involved in ex ante control of all or part of the procurement process. The consequence is that the regulatory body would be in a position to resolve complaints in cases where the PPO/PPA itself has already accepted (or even imposed) an allegedly wrong decision.

The same incompatibility can be noted in cases where the review body is directly involved in procurement transactions, for instance when it has been assigned, among other tasks, to act as a central procurement body.

In such cases the institution becomes the regulator, regulated, controller and judge, and a potential conflict of interest and abuse are almost unavoidable. These arrangements do not comply with the requirement of the independence of review bodies, and many countries have changed the institutional framework during the ongoing process of reforming the public procurement system.

Particular attention should be paid to the financing of the institution. A specialised review body has to be financially independent, with its own budget. Adequate funding is necessary to guarantee its independence and to ensure proper staffing (including administrative support staff) and other resources so as to provide services at the level of quality required. The best solution is to secure financing by means of the legal/regulatory framework. If the financing is inadequate or even in the case where the financing is adequate but is subject to administrative decisions and can be easily changed, the review body will not have real independence to fulfil its obligations.

The review body has to be provided with a sufficient infrastructure (e.g. office space, IT equipment, database and training) to successfully carry out its work.

With regard to the members of a specialised review body, their independence is an essential requirement for demonstrating the independent status of the review body as an institution. 
One of the most important aspects is the set of rules regulating the procedures of appointment and dismissal. The possibility of annulment of members' appointments, prior to the expiration of their mandate, has to be limited to only a few specific circumstances that have been very well defined in the law. The person/institution officially appointing members of the review body should be the same as the one with the power to dismiss them (only in the special circumstances provided for in the law). The more independent the person/institution with the legal powers to appoint/dismiss members of the review body, the more secure their position will be and hence their independence.

\begin{abstract}
Austria
The independence of administrative judges (permanent members Senatsvorsitzende) is guaranteed by constitutional law. The permanent members are appointed by the Federal President of Austria; the chairperson and deputy are nominated for life.

There are professional qualification requirements for appointment (specific knowledge of public procurement and legal experience). The chairperson, deputy and permanent members must be qualified lawyers with at least five years of professional experience in the practice of law or in the field of public procurement.
\end{abstract}

\title{
Slovenia
}

The National Review Commission (NRC) is a specialised, independent and autonomous national body reviewing public procurement award procedures, as prescribed in the Act on the Review of Public Procurement Procedures. The president and the four members of the NRC are appointed by the National Assembly, on a proposal from the Commission for Mandates and Elections, for a term of five years, with the possibility of re-election.

The president and two of the members must have a university degree in law and a vocational degree allowing admittance to the Bar. The other two members must have a university degree in economics or engineering.

In any case, the members of the review body must be protected by law from any interference or even pressure that might be exerted at the executive and/or political level. The members of the review body must exercise their functions with complete independence, and any instructions given, in the performance of their duties, on behalf of any other person must be prohibited by law.

The independence of review body members is a prerequisite for ensuring their impartiality, which is a fundamental principle of all judicial, quasi-judicial and administrative institutions. However, this impartiality may be affected by conflicts of interest that cannot be avoided and can arise naturally, without anyone being at fault. For this reason, the law or at least the regulations must provide rules on the identification and disclosure of conflicts of interest and propose actions that may be taken to avoid or mitigate them. Review body members should be excluded from participation in review proceedings whenever they have a private interest in the decision. For example, a member may be personally concerned or may be the relative of a person who is one of the parties in the dispute. In that event, it is appropriate for the member to maintain his/her position but refrain from participation in any decision-making process on the matters affecting him/her. This action can be taken by abstaining from a voting procedure, withdrawing from the discussions of relevant 
proposals, and refusing to receive any documents or other information related to the case.

As a general rule, review body members should be forbidden to:

- Perform commercial activities, including consultancy activities, directly or through intermediaries;

- Hold the quality of member of a group of economic interest;

- Hold the quality of member of a political party and perform or participate in political activities;

- Exercise any public or private function, except for activities in teaching, scientific research and/or literary and artistic creation.

Financial safety is another aspect that must be treated carefully when discussing the independence of the members of the review body. People in such positions could be exposed at any time to financial or other kinds of temptations, and they must be capable of withstanding such enticements. In those countries where the level of salaries in the public sector is generally lower, it is advisable to find a legal solution for implementing special salary schemes/grids in order to ensure a reasonable financial status for review body members.

\section{Romania}

The members of the National Council for Solving Complaints are public servants with a special status (independence, procedure of selection and appointment, incompatibilities and interdictions, salaries) and experience in the field of procurement law. The Council members are selected by competition, based on professional skills and reputation, and formally appointed by the Prime Minister. They must have a university degree and at least two years of professional experience in public procurement. At least half of the Council members must be qualified lawyers.

With regard to the level of remuneration, they are assimilated to the function of secretary general of the government.

\section{Other important practical issues}

It is not sufficient to simply describe "on paper" the kind of review body that should be put in place and the applicable general rules. A number of additional details need to be carefully addressed, as they are not expressly provided in the EU Remedies Directives but have a potential impact on the general principles of non-discrimination, effectiveness and transparency.

Concerning the observance of the principle of non-discrimination, the general understanding is that the access to remedies should be open to all economic operators without discrimination, especially on grounds of nationality.

Moreover, the principle of equivalence requires that, when there are specific remedies for the enforcement of EU rules, the conditions for application of these remedies should be "no less favourable" than the conditions for applying similar remedies to enforce 
domestic rules. Rules concerning access to the review body, fees to be paid, time limits and evidence to be submitted must therefore not render the exercise of rights conferred by law impossible or excessively difficult ${ }^{5}$.

For instance, the costs associated with review and remedies procedures should not be significant, as high costs may be seen as a disincentive for tenderers to submit complaints. Most of the EU Member States, in order to reduce the risk of abuse through fraudulent claims, apply an initial fee for filing complaints. However, the fees paid to first-instance review bodies are in any case lower than those paid for an appeal or for review by last-instance bodies. The fees should be proportionate, with a view to reducing the incentive to file fraudulent or unfounded complaints while not acting as a disincentive to the submission of justified complaints and not limiting the accessibility of small and medium-sized enterprises.

It is natural to provide in the law the most important elements that are to be included or attached to a complaint. However, the requirements regarding evidence should not be exaggerated or even impossible to fulfil. Economic operators may sometimes fail to provide certain documents/information or to accurately observe the format requested for some papers. In such cases, it is advisable to give these operators the opportunity to complete the file.

With regard to the observance of the principle of effectiveness, remedies must have sufficient authority (formal power) to ensure the observance of public procurement rules, and the review must be as rapid as possible. To achieve this objective, an operational review body is a prerequisite. The body's organisation, funding, staffing and authority to exercise its duties should be sufficient and consistent with its responsibilities.

Clear and detailed norms should be established in the law or at least at the level of implementing regulations, addressing procedural requirements and rules for the review process. Other issues also need to be clearly regulated, such as the way of allocating cases among the members of the review body - random distribution is probably the best choice where corruption is a serious threat, the means of avoiding conflicts of interest, and the qualifications required to become a member (studies, experience, knowledge and other specific skills). It is important to provide legal certainty as to whether the entire review body will decide on cases or whether panels will adopt the decisions. If the second option is preferred, the number of members on each panel should be indicated.

Procedural rules should be adopted to ensure the rapidity of proceedings, for example by laying down maximum deadlines for the decisions of the review body.

All of the above-mentioned norms not only benefit the establishment of an operational review body, but they are also in the interest of all of the stakeholders - contracting authorities/entities and economic operators - in terms of clearly stating what the rules are and what can be expected to occur during a review procedure.

The capacities of the review body have to be adequate for dealing with the expected number of appeals, and in time they must be strengthened in line with the overall development of the entire system. In terms of human resources in particular, administrative capacity will be reflected in staff size, the composition of staff and their educational backgrounds. 
If the institutions are continuously understaffed, their human resources capacity will not be sufficient to carry out their tasks effectively. The number of members of the review body should be determined by taking into consideration several important factors, such as:

- Range of tasks assigned to the review body, including not only the powers granted but also the scope of the review system ${ }^{6}$;

- Number of contracting authorities/entities in the country;

- Review culture, including local mentality and propensity of economic operators to file complaints against the decisions of contracting authorities/entities;

- Time limits provided in the law for deciding on the dispute;

- Number of members of the review body that, according to the law, have to deal with each case;

- Support that can be offered to the members of the review body by the technical and administrative staff of the institution.

The educational background of the staff working in the review body is also important, as its members must not only have a good knowledge of public procurement matters but must also be capable of assessing evidence and drafting substantiated decisions. The nomination of people to carry out review functions in the context of reforming the procurement system does not necessarily mean that they are, by that fact alone, competent to carry out those functions. The creation of a (new) review body will usually require a capacity-building effort, which would include intensive training, particularly at the beginning of the institution's activity but also in subsequent years through the participation in continuing education programmes.

A sensitive issue is to decide whether the review body is to consider only the contents of the complaint and limit the review exclusively to the pleas presented by the economic operators or whether it should also investigate more widely, considering the entire procurement documentation, in order to determine whether another major infringement of the law has occurred.

There are no EU requirements for ex officio investigations to be carried out by a review institution. Some countries have such provisions in their legislation, but many of them intend to abandon this requirement, as the outcome of these provisions has not always been positive in practice. In many cases, the applicants transferred the burden of investigation to the review body, which led to lengthy and costly procedures.

Important external support to the members of the review body could be provided if they have access to the use of external expertise to examine the technical aspects of a case. As a general rule, experts should have specialised knowledge in a particular area, and their task should be to provide the review body with impartial assistance on special matters, which are mostly technical or financial. Both the complainant and the contracting authority should be allowed to submit expert opinion(s). In addition, the review body might appoint its own expert, who must be impartial and independent from

6 In the largest group of EU Member States, the review system applies equally to contracts above and below the thresholds of the Public Procurement Directives 2004/17/EC and 2004/18/EC (for more details see Public Procurement Review and Remedies Systems in the European Union (SIGMA Paper No. 41, 2007). 
the parties and from any other influence. If the advice provided does not appear reasonable, the review body may reject it, appoint another expert, or adopt the findings of the parties' expert, if applicable.

Basically, it is not mandatory for members of the review body to adopt the opinion of experts, but this opinion can nevertheless have a considerable weight when making a decision and cannot be disregarded arbitrarily.

As for observance of the principles of legal certainty and of transparency, one of the most important objectives of the review body is to guarantee consistent decisions, which it should make publicly available.

A first condition is to have clear and transparent procedures in order to ensure the coherent application of the law. Second, each party should have the right to be informed of the development of the proceedings, so as to enable them to adequately prepare their arguments. Last but not least, the parties should have the right to be informed of the reasons for the review body's decision, including the arguments that determined the evaluation of the evidence and the considerations of legal issues that were relevant to the decision.

Publication of the review body's decisions on its website is an effective tool for helping its members to ensure the increasing consistency of the institution with previous resolutions in similar cases and to avoid conflicting decisions when interpreting the law. Moreover, it could also serve as a valuable instrument for sharing review body expertise with other key stakeholders in the system. Contracting authorities/entities and economic operators would benefit from this excellent way of promoting the solutions to the various complaints resolved by the institution and its interpretation of the various problems that the procurement system is facing.

Easy access to relevant data is necessary for increasing the efficiency of the "sharing" mechanism and for allowing the rapid search for cases that meet specific criteria. For this reason, the publication of the decision in a raw form (e.g. PDF document) would not suffice to guarantee the consistent interpretation and application of the law. It would be difficult for public procurement practitioners to quickly find solutions to legal problems, as reflected in these individual decisions, without reading all of them.

The best solution is to develop a database of decisions, including search facilities for individual legal problems as a means of support for practitioners in their daily procurement activities and also as an instrument for review body members to ensure consistent decision making. In addition, the review body should publish analyses of the most common legal problems encountered during procurement procedures, giving indications on how to deal with them in practice (e.g. qualification criteria, award criteria, use of technical specifications, abnormally low tenders).

Further reading:

- Public Procurement Review and Remedies Systems in the European Union, (SIGMA Paper No. 41, 2007);

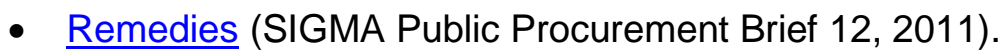

